\title{
BMJ
}

\section{Effectiveness of physiotherapy exercise after knee arthroplasty for osteoarthritis: systematic review and meta- analysis of randomised controlled trials}

\author{
Catherine J Minns Lowe, research fellow, ${ }^{1}$ Karen L Barker, director, ${ }^{2}$ Michael Dewey, special lecturer, ${ }^{3}$ \\ Catherine M Sackley, professor of physiotherapy research ${ }^{1}$
}

Department of Primary Care and General Practice, University of Birmingham

${ }^{2}$ Physiotherapy Research Unit, Nuffield Orthopaedic Hospital NHS Trust, Oxford

${ }^{3}$ School of Community Health Sciences, University of Nottingham

Correspondence to: CJMinns Lowe, Physiotherapy Research Unit, Nuffield Orthopaedic Centre NHS Trust, Oxford OX3 7LD catherine.minnslowe@noc.anglox. nhs.uk

doi:10.1136/bmj.39311.460093.BE

\section{ABSTRACT}

Objective To evaluate the effectiveness of physiotherapy exercise after elective primary total knee arthroplasty in patients with osteoarthritis.

Design Systematic review.

Data sources Database searches: AMED, CINAHL, Embase, King's Fund, Medline, Cochrane library (Cochrane reviews, Cochrane central register of controlled trials, DARE), PEDro, Department of Health national research register. Hand searches: Physiotherapy, Physical Therapy, Journal of Bone and Joint Surgery (Britain) Conference Proceedings.

Review methods Randomised controlled trials were reviewed if they included a physiotherapy exercise intervention compared with usual or standard physiotherapy care, or compared two types of exercise physiotherapy interventions meeting the review criteria, after discharge from hospital after elective primary total knee arthroplasty for osteoarthritis.

Outcome measures Functional activities of daily living, walking, quality of life, muscle strength, and range of motion in the knee joint. Trial quality was extensively evaluated. Narrative synthesis plus meta-analyses with fixed effect models, weighted mean differences, standardised effect sizes, and tests for heterogeneity. Results Six trials were identified, five of which were suitable for inclusion in meta-analyses. There was a small to moderate standardised effect size $(0.33,95 \%$ confidence interval 0.07 to 0.58 ) in favour of functional exercise for function three to four months postoperatively. There were also small to moderate weighted mean differences of 2.9 (0.61 to 5.2) for range of joint motion and 1.66 ( -1 to 4.3$)$ for quality of life in favour of functional exercise three to four months postoperatively. Benefits of treatment were no longer evident at one year. Conclusions Interventions including physiotherapy functional exercises after discharge result in short term benefit after elective primary total knee arthroplasty. Effect sizes are small to moderate, with no long term benefit.

\section{INTRODUCTION}

Osteoarthritis is the commonest cause of disability in older people, ${ }^{1}$ with painful knee osteoarthritis affecting
$10 \%$ of people aged over 55 in the United Kingdom. ${ }^{2}$ Over $80 \%$ of patients experience limitations in performing activities of daily living, such as mobility outside the home, household chores, and work duties. ${ }^{3}$ In 2005, patients with osteoarthritis accounted for at least 55495 primary knee joint arthroplasties in England and Wales. ${ }^{4}$ As the length of hospital stay after joint arthroplasty surgery has markedly and rapidly decreased, ${ }^{5}$ and given that patients who undergo knee arthroplasty may still experience considerable functional impairment postoperatively, ${ }^{6}$ the effectiveness of physiotherapy after discharge is a valid question. The present uncertainty regarding effectiveness makes it difficult for commissioning organisations, healthcare practitioners, and patients to make decisions regarding such physiotherapy. We systematically reviewed randomised controlled trials to determine the effectiveness of physiotherapy exercise after discharge in terms of improving function, quality of life, walking, range of motion in the knee joint, and muscle strength for patients with osteoarthritis after elective primary unilateral total knee arthroplasty.

\section{METHODS}

Searching

In March 2005 and in April 2007 we identified randomised controlled trials by simultaneously searching AMED (from 1985), CINAHL (from 1982), Embase (from 1974), Kings Fund database (from 1979), and Medline (from 1966) via Knowledge Access 24/7 (KA24). We also searched the Cochrane library, PEDro physiotherapy evidence database, and the Department of Health national research register. In July 2005 and April 2007 we handsearched Physiotherapy (1985- March 2007 inclusive) and Physical Therapy (1985-April 2007 inclusive) to double check for trials. The conference proceedings in the Journal of Bone and Joint Surgery (Britain) (1985-2006 inclusive) were also handsearched, as were the reference lists of included trials.

As it is difficult to locate physiotherapy trials, we considered that using multiple general searches was the optimum method. This review is part of a series that included both knee and hip search terms. Table 1 
summarises the searches. No language restrictions were applied.

\section{Selection}

We sought randomised controlled trials of patients undergoing elective total knee arthroplasty for osteoarthritis who received an intervention of physiotherapy exercise after discharge from hospital. We used broad definitions of "physiotherapy" and "exercise" to include any exercises or exercise programme advised or provided by physiotherapists or physical therapists during the rehabilitative period after discharge from hospital after surgery in the outpatient, community, or home setting. We excluded trials in which the intervention consisted of an electrical adjunct to physiotherapy, such as the use of continuous passive motion. Physiotherapy exercise interventions included outpatient physiotherapy sessions and functional physiotherapy programmes, in which exercises are based on functional activities. Trials were included if they investigated a physiotherapy intervention compared with usual or standard care or compared two different types of relevant physiotherapy intervention. Usual or standard care refers to the continuation of home exercise programmes provided to patients during a stay in hospital. These programmes usually consist of isometric or simple strengthening exercises, exercises to regain range of movement, and stretches. Effectiveness outcomes were measures of functional activities of daily living, walking, self reported measures of quality of life, muscle strength, and range of motion in the knee joint. As most trials use functional measures rather than specific pain outcomes, we did not include pain as an effectiveness outcome. Two

\section{Table 1 | Search strategy for systematic review}

Sources, searches, and search terms

Mar-Jul 2005 hits* (No of new relevant records)

KA24 (AMED 1985-, CINAHL 1982-, Embase 1974-, Kings Fund 1979-, Medline 1966-):

\begin{tabular}{|c|c|c|}
\hline $\begin{array}{l}\text { 1. "hip" OR "knee" (whole document) AND "replacement" OR "arthroplast\$" } \\
\text { (whole document) AND "rehabilitation" AND "trial\$" (whole document) }\end{array}$ & $587(25)$ & $180(0)$ \\
\hline $\begin{array}{l}\text { 2. "hip" OR "knee" (whole document) AND "replacement" OR "arthroplast\$" } \\
\text { (whole document) AND "rehabilitation" AND "trial\$" (title) }\end{array}$ & $118(11)$ & $1(0)$ \\
\hline $\begin{array}{l}\text { 3. "hip" OR "knee" (whole document) AND "replacement" OR "arthroplast\$" } \\
\text { (whole document) AND "physiotherapy" AND "trial\$" (title) }\end{array}$ & $2(0)$ & $4(0)$ \\
\hline $\begin{array}{l}\text { 4. "hip" OR "knee" (whole document) AND "replacement" OR "arthroplast\$" } \\
\text { (whole document) AND "physiotherapy" (title) }\end{array}$ & $39(0)$ & $14(0)$ \\
\hline $\begin{array}{l}\text { 5. "hip" OR "knee" (whole document) AND "replacement" OR "arthroplast\$" } \\
\text { (whole document) AND "physical therapy" (title) }\end{array}$ & $43(8)$ & $15(0)$ \\
\hline $\begin{array}{l}\text { 6. "hip" OR "knee" (whole document) AND "replacement" OR "arthroplast\$" } \\
\text { (whole document) AND "home programme" (title) }\end{array}$ & $2(0)$ & $1(0)$ \\
\hline $\begin{array}{l}\text { 7. "hip" OR "knee" (whole document) AND "replacement" OR "arthroplast\$" } \\
\text { (whole document) AND "home programme" (whole document) }\end{array}$ & $22(2)$ & $27(0)$ \\
\hline $\begin{array}{l}\text { 8. "hip" OR "knee" (whole document) AND "replacement" OR "arthroplast\$" } \\
\text { (whole document) AND "occupational therapy" (whole document) }\end{array}$ & $35(0)$ & $3(0)$ \\
\hline 9. "hip" OR “knee" (whole document) AND “occupational therapist\$” (title) & $0(0)$ & $3(0)$ \\
\hline \multicolumn{3}{|l|}{ Cochrane library (Cochrane reviews, CCRCT, DARE): } \\
\hline $\begin{array}{l}\text { 1. Browsed by topic-musculoskeletal, search narrowed-osteoarthritis, } \\
\text { search narrowed-rehabilitation }\end{array}$ & 9 & 11 \\
\hline 2. General search term "joint replacement" & 80 & 18 \\
\hline \multicolumn{3}{|l|}{ PEDro physiotherapy evidence database: } \\
\hline 1. "joint replacement AND rehabilitation" & $1(0)$ & $17(0)$ \\
\hline 2. "joint replacement" & $5(0)$ & $45(0)$ \\
\hline \multicolumn{3}{|l|}{ Department of Health national research register: } \\
\hline 1. "joint replacement AND rehabilitation" & 0 & $19(1)$ \\
\hline 2. "joint replacement AND physiotherapy" & 7 & $9(0)$ \\
\hline 3. "joint replacement AND exercise" & $2(0)$ & $6(0)$ \\
\hline 4. "joint replacement AND physical therapy" & $3(0)$ & $5(0)$ \\
\hline 5. "joint arthroplasty AND physiotherapy" & 0 & 0 \\
\hline 6. "joint arthroplasty AND rehabilitation" & $2(1)$ & $2(0)$ \\
\hline 7. "joint replacement AND occupational therapy" & $5(0)$ & $5(0)$ \\
\hline Physiotherapy key journal—hand search of contents pages & None new & None new \\
\hline Physical Therapy key journal-hand search of contents pages & None new & None new \\
\hline $\mathrm{JBJS}[\mathrm{Br}]$-hand search of all conference proceedings & 2 new & 1 \\
\hline Reference lists-hand searching of papers included in review & 1 new & None new \\
\hline Totals & $965(50)$ & $386(2)$ \\
\hline
\end{tabular}

2005-April 2007 hits* (No of new relevant records)

*Numbers after removal of duplicates commands when available. 
Table 2 | Quality component checklist and quality evaluation of six trials included in review

\begin{tabular}{|c|c|c|c|c|c|c|}
\hline Contained in study & $\begin{array}{l}\text { Codine et al, } \\
2004 w 1\end{array}$ & $\begin{array}{l}\text { Frost et al, } \\
2002 \mathrm{w} 2\end{array}$ & $\begin{array}{l}\text { Kramer et al, } \\
2003 w_{3}\end{array}$ & $\begin{array}{c}\text { Mockford and } \\
\text { Beverland } \\
2004 \mathrm{w}^{\star}\end{array}$ & $\begin{array}{l}\text { Moffet et al, } \\
2004 w 5\end{array}$ & $\begin{array}{l}\text { Rajan et al, } \\
2004 w 6\end{array}$ \\
\hline Rationale for study & Yes & Yes & Yes & Yes & Yes & Partial \\
\hline Eligibility criteria & Yes & Yes & Yes & Yes & Yes & Yes \\
\hline Recruitment method & No & Yes & No & Yes & Yes & Partial \\
\hline Settings and location of study & No & Yes & Yes & Yes & Yes & Yes \\
\hline Intervention & Partial & Yes & Yes & Yes & Partial† & No \\
\hline Objectives/hypotheses & Partial & Yes & Yes & Yes & Partial & Yes \\
\hline Defined outcome measures & Yes & Yes & No & Yes & Yes & Partial \\
\hline $\begin{array}{l}\text { Quality enhancers (such as multiple } \\
\text { observations) }\end{array}$ & No & Yes & Partial & & No & No \\
\hline Sample size determination & No & Partialł & No & Yes & Yes & Yes \\
\hline Randomisation & $\S$ & Yes & Yes & Yes & Yes & Yes \\
\hline Randomisation sequence generation & No & Yes & No & Yes & Yes & Yes \\
\hline Allocation concealment & No & Yes & No & Yes & Yes & No \\
\hline Randomisation implementation methods & No & No & No & Yes & Yes & No \\
\hline Blinding of participants & Inappropriate & Inappropriate & Inappropriate & Inappropriate & Inappropriate & No \\
\hline $\begin{array}{l}\text { Blinding of those administering } \\
\text { intervention }\end{array}$ & Inappropriate & Inappropriate & Partial & Inappropriate & Inappropriate & No \\
\hline Blinding of outcome/assessments & Yes & Yes & Yes & Yes & Yes & Yes \\
\hline Statistical methods & ף & Yes & Partial & Yes & Yes & Yes \\
\hline Flow of participants through each stage & No & Yes & Yes & Yes & Yes & Yes \\
\hline Recruitment and follow-up dates & No & Partial & No & * & Yes & Yes \\
\hline Baseline demographics & Partial & Yes & Yes & Partial & Yes & Partial \\
\hline Numbers analysed (and ITT) & No & Yes & Unclear & Yes & $\star \star$ & Yes \\
\hline Summary of results & No & Yes & Yes & Yes & Yes & Yes \\
\hline Estimated effect sizes & No & Yes & No & * & No & No \\
\hline Precision & No & No & No & * & Yes & Yes \\
\hline Results for each outcome & Yes & Yes & Yes & Yes & Yes & Yes \\
\hline Ancillary analyses & No & Yes & Unclear & * & Yes & No \\
\hline Adverse events & No & Yes & Partial & * & Yes & Partial \\
\hline Interpretation & Partial & Yes & Partial & * & Partial & Partial \\
\hline Generalisability & Partial & Yes & Partial & * & Yes & No \\
\hline Results placed into context & Partial & Yes & Partial & * & Yes & No \\
\hline $\begin{array}{l}\text { Quality (good enough to include in meta- } \\
\text { analyses) }\end{array}$ & No & Yes & Yes & Yes & Yes & Yes \\
\hline \multicolumn{7}{|c|}{$\begin{array}{l}\text { *Published abstract and information from authors only, therefore reporting is incomplete. } \\
\text { tIntervention described but little description of home exercise programme described to both groups. } \\
\text { †Feasibility trial that provided sample size calculations as part of results section. } \\
\text { §First participant was drawn randomly then alternatively assigned (this process was witnessed). } \\
\text { TAdditional information from author stated that sample size was determined by statistician who calculated } n=30 \text { in each arm to be sufficient. } \\
\star * \text { Intention to treat analysis intended and performed but per protocol analysis presented because loss to follow-up in control group favoured } \\
\text { intervention group. }\end{array}$} \\
\hline
\end{tabular}

reviewers (CML and CS) assessed and agreed on study eligibility.

Validity assessment, data abstraction, and quality assessment

We developed and piloted a data extraction form using quality indicators from the CONSORT statement ${ }^{7}$ and the CASP guidelines ${ }^{8}$ (table 2). Similar analysis of individual quality components has previously been used in reviews of physiotherapy ${ }^{9}$ and is advocated to avoid known problems associated with existing composite scores. ${ }^{10}$ Items could be marked as yes, no, unclear, or partial. Items were marked as yes only if they fully and explicitly met the detailed criteria laid out in the
CONSORT standards. ${ }^{7}$ Two reviewers (CML and KB) independently extracted the data. $\mathrm{KB}$ was masked to the key details of each paper and the extent to which masking was successful was assessed. The masking rates were $80 \%$ for authors, $20 \%$ for journals, $80 \%$ for author affiliations, and $80 \%$ for funding sources, all of which except journal of publication were considered successful. The level of agreement between reviewers was $69.09 \%$ ( $\kappa 0.524$, intraclass correlation coefficient (2,1) $0.49,95 \%$ confidence interval 0.30 to 0.63 ).

We resolved initial disagreements regarding study quality by discussion until consensus was reached. Major disagreement was rare; usually disagreement was the more minor "yes" to "partial/unclear" or 


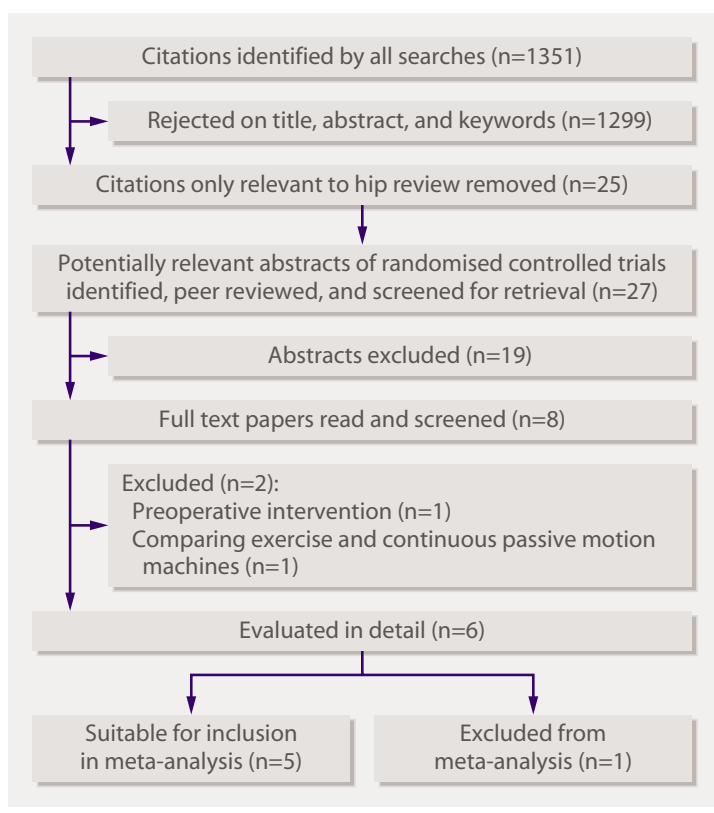

Fig 1| Trial flow diagram to summarise the stages of systematic review

"no" to "partial/unclear" and 100\% agreement was obtained. A third reviewer (CS) was available in the event of consensus not being reached, but this was not required. Where key study details were absent or unclear we contacted authors for further information.

We considered studies to be of good quality if they were good enough to include in meta-analyses. Table 2 presents quality assessment findings for each study. We excluded one study ${ }^{\mathrm{wl}}$ from the meta-analysis because participants were allocated by alternation. All trial outcomes were measured by assessors masked to allocation. As table 2 shows, most studies clearly reported the flow of participants through the trial, justified the sample size, and included intention to treat analyses. Several quality indicators were not fully discussed in all papers, such as allocation concealment and details regarding the implementation of randomisation methods.

\begin{tabular}{|c|c|}
\hline Reason for exclusion & Study \\
\hline Not a randomised clinical trial & $\begin{array}{l}\text { Tum-Sugden } 1976,{ }^{\mathrm{w} 7} \text { Ulreich et al } 1997,{ }^{\mathrm{w} 8} \text { Benedetti et al } \\
2003,{ }^{\text {w9 }} \text { Ritter et al } 1989,{ }^{\text {w10 }} \text { Waters } 1974^{\mathrm{w} 11}\end{array}$ \\
\hline Inpatient intervention & $\begin{array}{l}\text { Kolarz et al 1999, }{ }^{\text {w12 }} \text { Beaupré et al 2001, }{ }^{\text {w13 }} \text { Hewitt and } \\
\text { Shakespeare 2001, }{ }^{\text {w14 }} \text { Karst et al } 1995,{ }^{\text {w15 }} \text { Kim and Moon } \\
1995, \text { w16 Kumar et al 1996, w17 Montgomery and Eliasson } \\
\text { 1996, }{ }^{\text {w18 }} \text { Hughes et al 1993, }{ }^{\text {w19 }} \text { Lang } 1998,{ }^{\text {w20 }} \text { Munin et al } \\
1998^{\text {w21 }}\end{array}$ \\
\hline Osteopathic manipulation intervention & Licciardone et al $2004^{\mathrm{w} 22}$ \\
\hline Neuromuscular stimulation intervention & Stevens $2002^{\text {w23 }}$ \\
\hline Preoperative intervention & Gursen and Ahrens $2003^{\text {w24 }}$ \\
\hline $\begin{array}{l}\text { Comparison of exercise and continuous } \\
\text { passive motion }\end{array}$ & Worland et al $1998^{\text {w25 }}$ \\
\hline Study halted early with no results & Stanley $2004^{\text {w26 }}$ \\
\hline Duplicate trial report & Mockford et al $2006^{27}$ \\
\hline
\end{tabular}

\section{Quantitative data synthesis}

We carried out meta-analyses for knee function, walking, range of joint motion, and quality of life with R2.3.1 and the rmeta package. ${ }^{11}$ Our outcome was the score at the chosen time point rather than the change in score as this maximised the number of comparable studies. The time points used were three to four months after surgery and 12 months after surgery. If the same measure was reported we used weighted mean differences, otherwise we used standardised effect sizes (small (0.2), medium (0.5), and large $\left.(0.8)^{12}\right)$. We used fixed effect models and 95\% confidence intervals throughout and performed tests of heterogeneity $\left(\chi^{2}\right)$ at a 5\% significance level, though we accept these have low power because few studies were available for meta-analyses. We also calculated $I^{2}$ to give a measurement of the degree of heterogeneity between the trials in the meta-analysis. Random effects models were not considered as there was no compelling evidence of heterogeneity and estimating the variation between studies is difficult with such low numbers. The differences were calculated so that positive differences indicate that the effect favoured treatment and negative differences that the effect favoured control or usual care. We considered it inappropriate to assess publication bias because of the small number of trials.

\section{RESULTS}

We identified and screened 27 potentially relevant studies. Of these, six studies ${ }^{\mathrm{w1}-\mathrm{w} 6}$ were included in the systematic review and five ${ }^{\mathrm{w} 2-\mathrm{w} 6}$ in the meta-analysis (fig 1). Table 3 gives details of excluded studies. ${ }^{\text {w-w27 }}$ Table 4 provides the results of the analysis of heterogeneity.

\section{Study characteristics}

Table 5 summarises the characteristics of the included studies and provides information regarding the participants, interventions, main outcomes, and conclusions reached by authors.

\section{Summary of the interventions and comparisons}

With the exception of one trial, ${ }^{\text {w6 }}$ in-depth details of the intervention and comparison groups were available from the papers and authors (table 6).

The trial interventions were similar to each other in that they provided additional physiotherapy exercises or treatment after discharge after total knee arthroplasty, often involving programmes of functional

Table $4 \mid$ Heterogeneity $x^{2}$ and $I^{2}$ test ${ }^{\star}$ results for range of outcomes

\begin{tabular}{|c|c|c|}
\hline Outcome & $\begin{array}{l}\text { Three to four months } \\
\text { after surgery }\end{array}$ & 12 months after surgery \\
\hline Function & $X^{2}=0.78, d f=2, P=0.68$ & $X^{2}=2.35, d f=3, P=0.50$ \\
\hline Walking & $X^{2}=0.54, d f=1, P=0.46$ & $X^{2}=0.41, d f=1, P=0.52$ \\
\hline $\begin{array}{l}\text { Joint range of } \\
\text { motion }\end{array}$ & $X^{2}=1.46, d f=2, P=0.48$ & $X^{2}=2.28, d f=3, P=0.52$ \\
\hline Quality of life & $X^{2}=0.41, d f=1, P=0.52$ & $x^{2}=0.91, d f=2, P=0.63$ \\
\hline
\end{tabular}


Table 5 | Study characteristics of trials evaluated in systematic review

\begin{tabular}{|c|c|c|c|c|}
\hline Paper & $\begin{array}{l}\text { Operation and No of } \\
\text { patients }\end{array}$ & $\begin{array}{l}\text { Intervention (time of } \\
\text { intervention) }\end{array}$ & Main outcome measures & Results \\
\hline Codine et al, $2004^{\mathrm{w} 1}$ & Unilateral TKA, $n=60$ & $\begin{array}{l}\text { Submaximal training of hamstring } \\
\text { muscle using eccentric isokinetic } \\
\text { strengthening } v \text { control of usual } \\
\text { care (days } 10-30 \text { after surgery) }\end{array}$ & $\begin{array}{l}\text { Range of motion; isometric } \\
\text { muscle force; Knee Society } \\
\text { clinical rating scale }\end{array}$ & $\begin{array}{l}\text { Significant difference } \\
\text { between two groups for } \\
\text { extension only; favouring } \\
\text { intervention }\end{array}$ \\
\hline Frost et al, $2002^{\mathrm{w} 2}$ & $\begin{array}{l}\text { Unilateral TKA for } \\
\text { osteoarthritis, } n=47\end{array}$ & $\begin{array}{l}\text { Functional exercise group } v \\
\text { traditional exercise group (after } \\
\text { discharge) }\end{array}$ & $\begin{array}{l}\text { Leg extensor power; walking } \\
\text { speed; pain during walking } \\
\text { (measured using } 1 \text { item from } \\
\text { Oxford knee score); knee flexion }\end{array}$ & $\begin{array}{l}\text { Feasibility study. No } \\
\text { significant differences } \\
\text { between groups; trends in } \\
\text { favour of functional group }\end{array}$ \\
\hline Kramer et al, $2003^{\mathrm{w} 3}$ & $\begin{array}{l}\text { Primary unilateral TKA, } \\
n=160\end{array}$ & $\begin{array}{l}\text { Home based exercise group } v \\
\text { individual clinical based treatment } \\
\text { (generally beginning within } 1 \text { week) }\end{array}$ & $\begin{array}{l}\text { Knee society clinical rating scale } \\
\text { scores; WOMAC; SF-36; walk } \\
\text { test; knee flexion. }\end{array}$ & $\begin{array}{l}\text { No significant differences } \\
\text { between groups }\end{array}$ \\
\hline $\begin{array}{l}\text { Mockford and Beverland } \\
2004^{\text {w4 }}\end{array}$ & TKA, $n=150$ & $\begin{array}{l}\text { Outpatient physiotherapy } v \text { control } \\
\text { of usual care ( } 3 \text { weeks after } \\
\text { discharge) }\end{array}$ & Range of motion & $\begin{array}{l}\text { Significant difference in } \\
\text { range of motion favouring } \\
\text { intervention }\end{array}$ \\
\hline Moffet et al, $2004^{\mathrm{w5}}$ & $\begin{array}{l}\text { Primary unilateral TKA } \\
\text { for osteoarthritis, } \\
n=77\end{array}$ & $\begin{array}{l}\text { Functional rehabilitation sessions } \\
v \text { usual care ( } 2 \text { months after } \\
\text { surgery) }\end{array}$ & $\begin{array}{l}\text { Functional ability: distance } \\
\text { walked in } 6 \text { minutes; SF-36; } \\
\text { WOMAC }\end{array}$ & $\begin{array}{l}\text { Significant difference in } \\
\text { walking distance for } \\
\text { functional group. At } 2 \text { and } \\
4 \text { month follow-up (but not } \\
\text { 12) functional group had } \\
\text { less pain, stiffness, and } \\
\text { difficulty performing } \\
\text { activities of daily living }\end{array}$ \\
\hline Rajan et al, $2004^{\mathrm{w} 6}$ & $\begin{array}{l}\text { Primary TKA for } \\
\text { monoarticular } \\
\text { arthrosis, } n=120\end{array}$ & $\begin{array}{l}\text { Outpatient physiotherapy } v \text { no } \\
\text { outpatient physiotherapy alone } \\
\text { (after discharge) }\end{array}$ & Range of motion in degrees & $\begin{array}{l}\text { No significant differences } \\
\text { between groups }\end{array}$ \\
\hline
\end{tabular}

TKA=total knee arthroplasty; WOMAC=Western Ontario and McMaster Universities osteoarthritis index.

weight bearing exercise. The study by Rajan et al provided few details regarding the intervention. ${ }^{\text {w6 }}$ Though most interventions included functional weight bearing exercises, Codine et al investigated the effect of eccentric isokinetic muscle strengthening with a CYBEX dynamometer. ${ }^{\text {w1 }}$ Interventions usually started within two weeks of discharge. Outpatient programmes generally lasted up to 12 weeks, while home exercise programmes were recommended for up to a year or indefinitely in one case. ${ }^{\mathrm{w} 3}$

The comparison groups were mainly control groups in which no additional outpatient physiotherapy was organised. Patients were expected to continue with the traditional home exercise programme-namely, isometric strengthening and range of movement exercises plus gait training or re-education provided to all patients during their stay in hospital.

\section{Quantitative data synthesis}

\section{Measures of function (five trials)}

Five of the studies contained a measure of function. ${ }^{\text {w1-w5 }}$ The measures used included the 12 item Oxford knee score,${ }^{\mathrm{w} 4}$ which measures functional ability, including pain, (scores 12-60, low score indicates high function) (Frost et al used one item of this score ${ }^{\mathrm{w} 2}$ ); the American Knee Society clinical rating score, ${ }^{\text {w1 w3-w4 }}$ which measures pain, movement, stability, and functional activity (scores 0-100, high score indicates favourable); the 24 item Western Ontario and McMaster Universities osteoarthritis index (WOMAC), ${ }^{\text {w3 w5 }}$ which has domains for pain, stiffness, and function (scored as a percentage by Moffet el $\mathrm{al}^{\mathrm{w} 5}$ and out of 0-170 for function by Kramer et $\mathrm{al}^{\mathrm{w} 3}$ (low scores are favourable)); and the Bartlett patellar score, ${ }^{\mathrm{w} 4}$ which measures anterior knee pain, quadriceps strength, and function (scores 330, high scores are favourable).

Within the individual trials, three found no significant differences between groups. ${ }^{\text {wl-w3 }}$ Frost et al found significant differences within groups for the treatment arm, indicating a benefit of treatment. ${ }^{\text {w2 }}$ Mockford and Beverland presented no results in their published abstract but supplied summary statistics for their outcomes, ${ }^{\mathrm{w} 4}$ allowing us to include their study in the meta-analysis. Moffet et al found significant differences between the two groups, in favour of the intervention, at four and six months after arthroplasty but not at 12 months. ${ }^{\text {w5 }}$

Figure 2 shows the three studies with data on functioning at three to four months and 12 months after

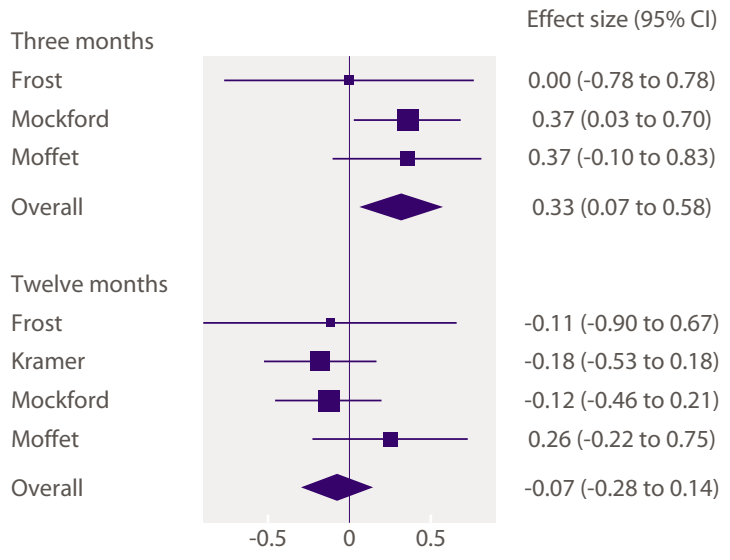

Fig 2 | Forest plot of standardised effect sizes with confidence intervals for function and results of test for heterogeneity 
surgery. Where studies included more than one measure of function we decided to use the Oxford knee and the WOMAC scores as these encompassed all component trials. No trial included both these scores. At three to four months the standardised effect size was 0.33 (95\% confidence interval 0.07 to 0.58 ), which is considered small to moderate. ${ }^{12}$ At 12 months, with one additional study, the effect size was close to zero at -0.07 and the confidence interval $(-0.28$ to 0.14$)$ included zero.
Walking (three trials)

Three knee arthroplasty trials used some form of outcome measure for walking. ${ }^{\text {w2 w3 w5 }}$ The measures reported included walking speed over a 10 metre distance, measured in $\mathrm{m} / \mathrm{sec},{ }^{\text {w2 }}$ and a six minute timed walking test, measured in metres. ${ }^{\text {w3 }}{ }^{\mathrm{w} 5}$ The study by Moffet et $\mathrm{al}^{\mathrm{w} 5}$ reported on time walking over a 50 metre walkway.

The results from these trials were mixed. One trial found no significant differences between groups, ${ }^{\text {w3 }}$

Table 6 | Summary of trial interventions and comparisons included in the knee replacement trials $(n=6)$

Early programme provided to all trial participants

Codine et al, 2004 ${ }^{\mathrm{w} 1} \quad$ Knee mobilisation (continuous passive motion and manual), isometric muscle strengthening for all knee and leg muscle groups, "proprioceptive enhancement," walking exercises
Frost et al, $2004^{\mathrm{w} 2} \quad$ Gait re-education, mobilising, and strengthening exercises (including active knee flexion, straight leg raises, inner range quadriceps, isometric quadriceps)

\section{Intervention details}

Submaximal hamstrings muscle eccentric isokinetic strengthening (passive resist mode). Torque produced $>$ half of torque measured during testing. CYBEX dynamometer training speed of 10 degrees/s. Range of motion during flexion was conducted in active assist mode. Programme from day 10-30 post total knee arthroscopy, CYBEX 5 mins/day, 5 days/week for 3 weeks

Warm up: sitting knee flexions 10 repetitions. Chair rise:

baseline number set and increased every alternate day up to 2 mins, then repeat up to 3 times/day;. Walk: 1 min normal pace, increase $30 \mathrm{~s} /$ day until up to 10 mins, repeat 2-3/day. Leg lifts on to step/thick book: Baseline set. Increase by 1 per day until 2 min duration. Then repeat 2-3/day

Kramer et al, $2003^{\text {w3 }}$ Performed 3 times/day until 12 week check-up, then $\geq$ once a day. Stage I-supine: knee flexion and extension. Long sitting: autoassisted knee flexion, ankle dorsiflexion in knee extension with calf stretch. Supine: isometric knee extension, inner range quadriceps. Supported sitting: hamstrings stretch. Sitting: active knee extension. 10 repetitions. Stretch/holds for $5 \mathrm{~s}$. Stage II-prone lying: quadriceps stretch. Standing: quadriceps stretch, soleus stretch, Achilles stretch, knee flexion (progress to ankle weights). Supine: straight leg raise. Sitting: resisted knee extension, resisted knee flexion, sit-stand-sit. 10 repetitions, stretch/holds for $5 \mathrm{~s}$. Optional exercises: exercise bike; standing wall sits 5-10 repetitions; standing slow short squats 10 repetitions.

Mockford and Supine: active ankle dorsiflexion and plantarflexion

Beverland, 2004 ${ }^{\mathrm{w} 4} \quad$ (10 repetitions), isometric quadriceps and hamstrings (3 repetitions), straight leg raise (repetitions vary), physiotherapist assisted knee flexion (5 repetitions), heels slides ( 3 lots of 10 repetitions, 2 mins rest between each set), active knee extensions over roll/bar (3 sets of 10 repetitions, as able, 2 mins rest between each set). High sitting: proprioceptive neuromuscular facilitation. Hamstrings pulley with $2 \mathrm{~kg}$ weight ( 3 lots of 10 repetitions, 2 mins rest between each set). Gait re-education with crutches/sticks as appropriate. Stairs practice
Outpatient physiotherapy weeks 2-12 after surgery: up to two sessions/week, each session about 1 hour. Exercises could be added/modified, therapeutic modalities (ice, heat,

ultrasound), joint mobilisations, or other measures as appropriate. Patients requested to complete common home

exercise only twice on clinic session days

\author{
.
}

weeks 1,2 , and 3, and 1 session in weeks 4-6). Week 1 -heel

slides, isometric quadriceps and hamstrings, straight leg raise,

active knee extension over bar/roll and hamstrings pulley-all

as in early programme. Proprioceptive neuromuscular

facilitation, physiological mobilisations for flexion and extension ( 3 sets of 10 repetitions with 2 mins rest between

sets). Weeks 2-3-standing: weight shifts (10 repetitions),

quarter squats (10 repetitions). Prone lying: autoassisted

quadriceps stretch (10 repetitions). Sit-stand-sit (10

repetitions). Gait re-education. Weeks 4-6-proprioceptive

outpatient physiotherapy

9 outpatient physiotherapy sessions in 6 weeks ( 2 sessions in No outpatient physiotherapy work in parallel bars. Gait re-education. Standing: stepping over cones, wobble board, step-ups (10 repetitions). Exercise bike for 5 mins

Moffet et al, 2004 ${ }^{\mathrm{w5}} \quad$ "Simple exercises" to regain lower limb strength (quadriceps, 12 sessions of outpatient physiotherapy in 6-8 weeks, hamstrings, hip abductors, and hip extensors) and to increase 60-90 mins each at clinic visit starting 2 months after surgery. knee range of motion. Advice about knee positioning, ice application, and gait retraining

Plus individual home exercise programme. Warm up

(5-10 mins): lower limb flexion/extension, alternate ankle dorsiflexion-plantarflexion, hamstrings stretch. Specific strength exercises (15 mins): isometric knee extension in $0^{\circ}$ and $60^{\circ}$ flexion at visits $1-2$; isometric hamstrings $60^{\circ}$ flexion at visits 3-6: concentric eccentric hip abductors against gravity at visits $1-4$. Functional task oriented exercises (15-20 mins): get up-sit down at visits 1-6; knee extensor strengthening in standing with Theraband at visits 1-6; controlled bilateral knee flexion-extension in standing at visits 1-8; unilateral knee flexion to $90^{\circ}$ in standing at visits 7-10; climbing on platform/stairs at visits 3-12; walk backwards on slope and/or laterally while crossing lower limbs at visits 3-12: walk in place, with large amplitude hip and knee flexion and upper limb movements at visits 9-12. Endurance exercises (5-20 mins): walk at visits 3-12, exercise bike at visits 4-12. Cool down (10 mins), slow walk, strength, ice visit. No attempt made to limit care. Information about usual care obtained by questionnaire and by phone interviews with patients and physiotherapist

Long sitting: static quadriceps ( $5 \mathrm{~s}$ old); straight leg raise ( $5 \mathrm{~s}$ hold). Supine: knee flexion heel slides. Standing: knee flexion ( 5 s hold) Sitting: long arc quads ( 3 s hold)

Physiotherapist phoned patient $\geq 1$ uring weeks 2-5 and 7-12 after surgery for queries, advice. Patients able to phone with queries 


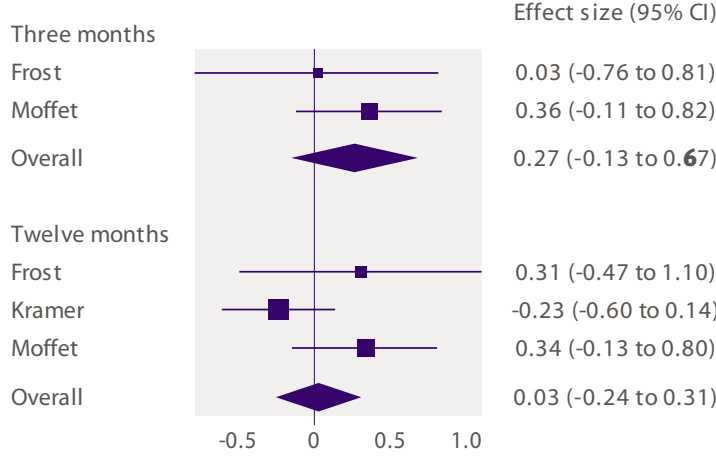

Fig 3 | Forest plot of standardised effect sizes with confidence intervals for walking

another found differences approaching significance, ${ }^{\mathrm{w} 5}$ and the third trial found significant differences within intervention groups. ${ }^{\text {w2 }}$ Figure 3 shows that the intervention had no overall influence on walking at either three or 12 months.

\section{Range of joint motion (five trials)}

Five of the total knee arthroplasty trials used the range of motion in the knee joint as an outcome measure. ${ }^{\text {w1-w4 w6 }}$ Although all measurements were provided in degrees, the method of achieving results varied. Codine et al used a goniometer integrated into a dynamometer to measure knee flexion and extension, ${ }^{\text {w1 }}$ while Mockford and Beverland used a goniometer to measure active and passive flexion and extension. ${ }^{\mathrm{w} 4}$ Frost et al ${ }^{\mathrm{w} 2}$ and Kramer et al ${ }^{\mathrm{w} 3}$ both measured active flexion only, and Rajan et al measured range of motion in the knee as a single value. ${ }^{\text {w6 }}$

Once again, the results were mixed. Codine et al found a significant difference in knee extension between the two groups at 10 days, ${ }^{\mathrm{w} 1}$ though, despite randomisation, extension was different in the two groups at baseline. Another study concluded that there was a significant difference in active knee

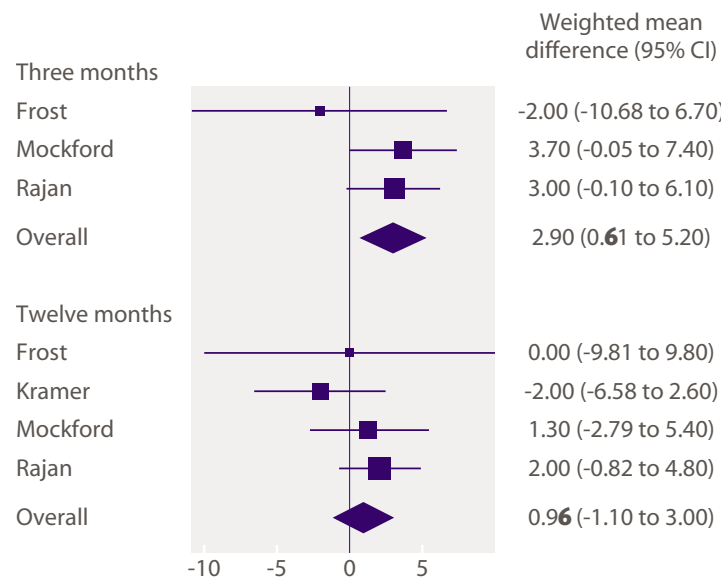

Fig 4 | Forest plot of weighted mean differences with confidence intervals for range of motion (in degrees) movement in favour of the intervention group but not in the passive range. ${ }^{\mathrm{w} 4} \mathrm{In}$ the pilot study by Frost et $\mathrm{al}^{\mathrm{w} 2}$ there was a trend for less loss of range in the functional group than in the traditional exercise group but the study was small and the difference was not significant. Two other studies also found no significant differences. ${ }^{\text {w3 }}$ w6

All the studies on range of movement in the knee joint used the same measure (degrees); therefore figure 4 shows the weighted mean differences and confidence intervals. The three month summary shows an increase of $2.9^{\circ}\left(0.61^{\circ}\right.$ to $\left.5.2^{\circ}\right)$, which is considered small to moderate. At 12 months the effect was smaller, about $1^{\circ}$, and the confidence interval $\left(-1.10^{\circ}\right.$ to $\left.3.00^{\circ}\right)$ included zero.

\section{Quality of life (three trials)}

Three trials included measures of quality of life. . $^{\text {w3-w5 }}$ The SF-36 health survey provides an eight scale profile of functional health and wellbeing scores with low scores indicating poor health. Kramer et al ${ }^{\text {w3 }}$ used the SF-36, and Moffet et al used a French translation of the same score. ${ }^{\mathrm{w} 5}$ Moffet et al also provided the physical component and mental component scores of the SF$12,{ }^{\text {w5 }}$ as did Mockford and Beverland. ${ }^{\mathrm{w} 4}$

One trial found no significant differences between the groups. ${ }^{\text {w3 }}$ One other trial has not yet presented statistical analyses for this measure. ${ }^{\mathrm{w} 4}$ The final trial found small significant differences in favour of the intervention group for the role-physical dimension of the SF-36 and the physical and mental component scores at six month follow-up but not at 12 month follow-up. ${ }^{\text {w5 }}$

Figure 5 presents the studies with data on quality of life. At three to four months the studies used the same measure, the SF-12, and so we have presented weighted mean difference results. At 12 months after surgery, however, not all studies used the same measure and therefore we used standardised effect sizes.

At three to four months after surgery the weighted mean difference was 1.7 (-1.0 to 4.3), indicating a small effect in favour of the intervention. At 12 months the

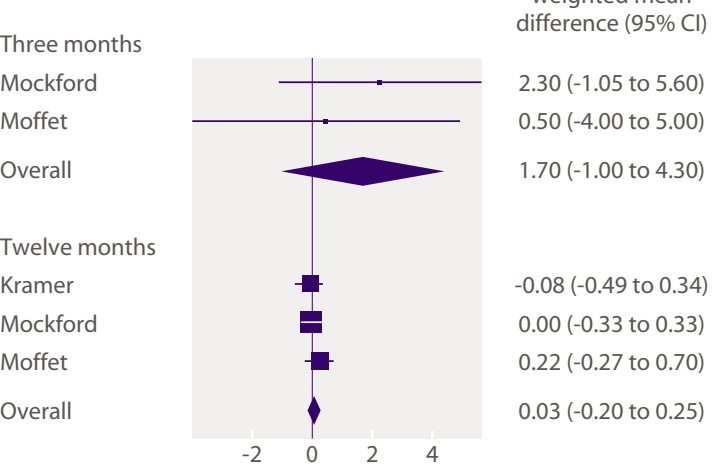

Fig 5 | Forest plot of weighted mean difference (three to four months) and standardised effect size (12 months) with confidence intervals for quality of life 
effect was close to zero with a standardised effect size of $0.03(-0.20$ to 0.25$)$.

\section{Muscle strength}

None of the trials included in the review directly measured muscle strength.

\section{DISCUSSION}

This systematic review provides support for the use of physiotherapy exercise interventions with exercises based on functional activities after discharge, rather than traditional home exercise and advice programmes, to obtain short term benefit after elective primary knee arthroplasty. There was a small to moderate standardised effect size in favour of functional exercise for function three to four months postoperatively. Small to moderate weighted mean differences, in favour of functional exercise interventions, were seen for range of joint motion and quality of life three to four months postoperatively. Any benefits seen after treatment did not persist to one year follow-up.

\section{Strengths and weaknesses of review procedures}

Physiotherapy literature remains a difficult area to search, with numerous bibliographic databases and unindexed journals. ${ }^{13}$ While we made every attempt to identify studies in any language, other studies might exist. We believe, however, that this review remains the most comprehensive to date.

Trial quality was good overall. Of the five adequately randomised studies included in the meta-analyses, most were sufficiently powered with adequate strategies to conceal allocation and outcome measurements obtained by assessors blinded to treatment allocation. ${ }^{7}$ Yet, like most physiotherapy trials, ${ }^{14}$ studies were relatively small, with 554 participants in the five trials included in the meta-analyses and 614 participants included overall in the review.

The most commonly used outcomes were function, predominantly subjective measures of functional ability, and range of joint motion as an objective measure. While range of joint motion is important, its usefulness as an outcome measure of physiotherapy interventions is limited as other factors, such as prosthetic design, preoperative knee motion, and surgical technique, also influence postoperative range of joint motion. ${ }^{15}$ None of the trials directly measured muscle strength, although one included leg extensor power, ${ }^{\text {w2 }}$ instead studies used objective measures like walking.

There were no apparent problems with our data extraction processes. Although many quality checklists and scales exist, there is no accepted ideal score; component approaches are often preferred as the wide variety of scores and weighting systems available mean that the same trial may score as both high quality and low quality depending on which score is used. ${ }^{10}$ Additionally, many scoring systems downgrade the quality rating of a trial if it is not double blinded. For many physiotherapy trials, such as those in this review, patients and therapists inevitably know the treatment allocation and this is not an indication of low or high trial quality. For these reasons we used a component approach, although we accept this is controversial.

The $\chi^{2}$ tests did not indicate major problems with heterogeneity in any of the eight analyses, but these were limited by low power. The $I^{2}$ results also indicated no observed heterogeneity. ${ }^{16}$ The number of available studies, and their size, does limit this review and prevents its findings from being conclusive. It is perhaps surprising that so few published trials exist for such a common practice. This may be partially attributable to the general lack of research on rehabilitation in orthopaedic surgery patients after discharge, rather than knee arthroplasty patients as such, as we also found few existing trials investigating exercise and rehabilitation after elective hip arthroplasty.

\section{Clinical implications}

Presently, given the reduction in length of hospital stay, compressed inpatient rehabilitation, and the limitations of the available evidence, it seems reasonable to refer patients for a short course of physiotherapy after discharge to provide short term benefit. While range of motion may be limited as an outcome measure of physiotherapy, the small to moderate standardised effect size obtained for function, which favours the intervention, is considered clinically important. This reflects actual improvements in one or more important aspects of function reported by patients after they received the treatment intervention. The type of physiotherapy provided also needs consideration. In the short term physiotherapy exercise interventions with exercises based on functional activities may be more effective after total knee arthroplasty than traditional exercise programmes, which concentrate on isometric muscle exercises and exercises to increase range of motion in the joint.

\section{Future directions}

Although there were few studies and they were not large, they are still likely to have detected most worthwhile effects. These tentative findings suggest that further research would be worthwhile to reduce the current level of uncertainty. ${ }^{17}$

There seemed to be no benefits related to treatment at one year, though the evidence is not conclusive. The content of the intervention could be better designed and further tested. Interventions to date have largely consisted of exercise programmes and gait rehabilitation, mainly targeting impairment and helping patients to recover from the effects of surgery rather than specifically targeting limitations in activity or restrictions in participation. From the wider field of rehabilitation as a whole, however, such task training seems highly relevant. A recent systematic review, which assessed physiotherapy on functional outcome after stroke, found that effective studies contained focused exercise programmes within which the relevant functional tasks were directly trained. ${ }^{18}$ Research is currently underway to determine whether a brief feasible physiotherapy intervention of this type, supplied after discharge, affects patient's functional ability one year 


\section{WHAT IS ALREADY KNOWN ON THIS TOPIC}

Osteoarthritis is the commonest cause of disability in older people, and total knee joint arthroplasty is a common orthopaedic procedure

Uncertainty exists regarding whether physiotherapy after discharge should be routinely provided to patients after elective primary knee arthroplasty for osteoarthritis

\section{WHAT THIS STUDY ADDS}

Functional physiotherapy exercise soon after discharge results in short term benefit after elective primary knee arthroplasty

No benefit was seen at one year
2 Peat G, McCarney R, Croft P. Knee pain and osteoarthritis in older adults: a review of community burden and current use of primary health care. Ann Rheum Dis 2001;60:91-7.

3 Fautrel B, Hilliquin P, Rozenberg S, Allaert FA, Coste P, Leclerc A, et al. Impact of osteoarthritis: results of a nationwide survey of 10,000 patients consulting for OA. Joint Bone Spine 2005;72:235-40.

4 National Joint Registry for England and Wales. 3rd Annual clinical report 2005:8-9. www.njrcentre.org.uk/documents/reports/annual/ 3rd/NJR_AR2_LR.pdf.

5 National Audit Office. Hip replacements: an update. London: Stationery Office, 2003 (HC 956).

6 Noble PC, Gordon MJ, Weiss JM, Reddix RN, Conditt MA, Mathis KB. Does total knee replacement restore normal knee function? Clin Orthops Rel Res 2005;413:157-65.

7 Altman DG, Schulz KF, Moher D, Egger M, Davidoff F, Elbourne D, et al. The revised CONSORT statement for reporting randomized trials: explanation and elaboration. Ann Intern Med 2001;134:663-94

after knee arthroplasty. An investigation into the health economics is also included.

We thank Robert Bourne, David Beverland, P Codine, Helen Frost, Patricia Humphreys, John Kramer, and Brian Mockford for providing additional data for the review. Mike Clarke and students on the "Systematic Reviews" Module, May 2005, University of Oxford Department for Continuing Education, commented on the design of the review during its planning.

Contributors: CJML designed the review, undertook the review searches, screened trials for eligibility, assessed the quality of the trials, assisted with data analysis, and drafted the paper. She is guarantor. KLB supervised the review, assessed the quality of trials, and reviewed the draft paper. MD designed and undertook the meta-analyses for the review and reviewed the draft paper. CMS supervised the review, screened trials for eligibility, and cowrote the paper. Funding: CJML is funded by a nursing and allied health professional researcher development award from the Department of Health and NHS research and development. CMS is funded by a primary care career scientist award from the Department of Health and NHS research and development. Competing interests: None declared.

Ethical approval: Oxford local research ethics committee (AQREC No A03.018).

Provenance and peer review: Not commissioned; peer reviewed.

1 Martin J. Meltzer H, Elliot D. OPCS surveys of disability in Great Britain. 1. The prevalence of disability among adults. London: HMSO 1988. 